\title{
XXVI. On the tides
}

\section{Laplace}

To cite this article: M. Laplace (1816) XXVI. On the tides, Philosophical Magazine Series 1, 47:214, 118-125, DOI: $10.1080 / 14786441608638811$

To link to this article: http://dx.doi.org/10.1080/14786441608638811

曲 Published online: 27 Jul 2009.

Submit your article to this journal

Џ Article views: 3

Q View related articles $₫$ 
by a professional gentleman who had previously tried it in Walls End and Hebburn collieries; and its merits appear to be still greater than those of Mr. Stephenson's. The lamp being suspended in a ressel of glass open at the top, and the carburetted hydrogen admitted from below, the bright flame of the wicks nearly disappeared, but the cylinder of wire-gauze was filled with a feeble but steady greenish light. On a greater volume of inflammable air being thrown in, the fiame gratually died out. Results more satisfactory could not be expected nor wished for, particularly when we were assured that these accorded with numerous trials made in the most hazardous drifts of our coalmines.

Notwithstanding all that has been lately said in some of the periodical publications, respecting the obstinacy of the riewers employed here, and the stupidity of their under agents and pitmen, you may depend upon it that these safe-lamps are bitled by this class of people as a most fortunate discovery, which will soon be adopted by them in every mine infected with fire-damp. And could a mode be struck out, of preventing infammation taking place by means of the furnace placed at the buttom of the upcast shaft to accelerate the circulation of air through the worliings, little would be wanting to render the occupation of the collier as safe at least as that of the persons employed in leat and copper mines.

Your most obedient servant,

Newcastle-upon-Tyne, Feb. 16, 1810.

N.

XXVI. On the Tides. By M. LapLace*.

[Read to the first Class of the Institute the 10/h of July $18: 5.1]$

$\mathrm{T}$

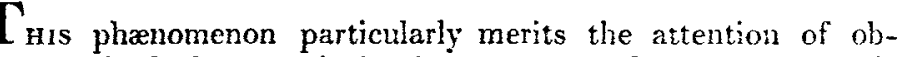
servers, both because it is the nearest and most perceptible effect of the action of the heavenly bodies, and because the ninmerous varieties it presents are well calculated to verify the law of universal gravitation. At the request of the Acadsmy of Sciences a course of observations were made at the beginning of the last century in the port of Brest, which were contimued $1 / 3$ ring six successive years, and of which the greater part have been published by Lalande in the fourth volume of his Astronomie. The situation of the port is very favourable for observations of this kind. It communicates with the sea by meaus of a cant,

* From the Connoissance des Tems for 1818.

f For this transliztion we are indebted to T.S. Evans, jun. of the College schoul, Gloucester. 
terminating in a very large road, at the extremity of which the port has been built. "Thus the irregularities of the motion of the sea are considerably weakened before they reach the port, very nearly in the same manner as the oscillations produced in the barometer by the irregular motion of a vessel, are diminished by a contraction in the tube of this instrument. In other respects the tides being conviderable at brest, the casual variatrous occasioneal by winds form only a small part of them. it may also be remarked in the observations made of these tides, however few there may be of them, that a great regularity prevails which is not altered by the little river, which loses itself in the immense roal of this port. Struck with this regularity, I solicited government to order a new course of olservations to be marle at Brest, during an entire period of the motion of the nodes of the lunar orbit. They had long been wished for. 'These new observations are dated from the lst of June 1806, and sirce that period they have been continued uniuterruptedly to this day, There is still, liowever, much wanting. 'They relate neither to the same part of the port, nor to the same scale. The observations of the first five years have been made at the place called $L$ a Miture, the others were taken near the bason. I observe that this change has produced only slight differences; but it would have been better, undoubtedly, if all the observations had been made at the same place and upon the same scale. It is time, indeed, that phænomena of this nature should be observed with the sane care as those of astronomy.

In these new ohservations 1 have considered those of the year 1807 and of the seven sulsequent years. In each equinox and in each solstice I have chosen the thrce syzygies and the three quadratures nearest to this equinox and this solstice. In the syzygies I have taken the excess of the high water of the evening above the low water of the moruing of the day which precedes the syzygy, of the day of the syzygy, and of the four following days, becimse the highest tide hrappens about the middle of this interval. I have marle a sum of these excesses corresponding to each day, by doubling the excesses which relate to the intermediate syzygy, or that nearest to the equinox or the solstice. By this means the effects produced by the variation of the distances of the sun and of the moon from the earth are destroyed: for if the moon were, for example, towards its perigeum in the intermediate syzygy, it would be near its apogeum in the two extreme syzygies. The sums of the excesses thus obtained are, therefore, very nearly independent of the variations of the motion and of the distances of the heavenly bodies. There are still inequalities of the tides, different from that inequality, whose period is aloout half a day, and which in our ports is $\mathrm{H} 4$ 
muen greater than the others. For by considering at the same time the obsermations at the two equinoxes and at the two solstices, the effect of the small inequality, whose period is pearly a diny, is mutually destrored. The sums in question are consequently cuirely owing to the great incquality. The winds can bave little infuence on them; for, if they raise the high water, they rust esually depress the low water. I have determined the law of these sums for each year, by observing, that their variation is very nearly proportional to the square of their distance in time from the maximum which has given me this maximum; its distance at the mean of the times of the syzyg tides, and the coeficient of the square of the times in the law of the variation. With regard to this coefficient, the little difference which the obserwations of each year present, proves the resularicy of these observations: and according to the laws which I have elsewhere established, on the probability of results dexluced from a great number of observations, some judgenent may be formed of the accuracy of results determined from the whole of the observations of eight years.

In the same mamner I have considered the quadrature tides, by taking the excess of the high water in the morning above the Jow water of the evening of the day of the quadrature, and of the three following days. The increase of the tides, beginning from the mininum, bcing much more rapid than their decrease, beginning from the maximum, I have thought it necessary to confune the lav of the variation proportional to the square of the time within a much shorter interval.

In all these results the infucnce which the declinarions of the heavenly bodies have on the tides, and upoin the law of their variation in the syyjies ent in the quadratures, is evidently shown. fi considering, by the same methol, eighteen equinoctial syzgy tides towards both the perigeum and the apogemn of the moon, the influenge which the changes of the lunar distance have upon the beinh and upon the law of variation of the tides, is manifered with the same degree of evidence. It is thus that by combining obervations in such a way as to buing ont every clemont, which we are desirous of knowing, we are able to separate the laws of the phisnonena when nixed and contounded together in the collertivis of obserrations.

After having obtained the results I have just mentioned, I conpared then with the thesry of the tides delivered in the fourth book of the Mecanigue ifeste. This theory is founded on a principle of dyamics, which renders it very simple, and independent of the local circumstances of the port, which circumstances are too complicated for the possibility of submitting them to calculation. By means of this principle, they enter 
into the results of the analysis a"s abitrary quantities, which ought thus to represent the observations, if the universal gravitation is in fact the true cause of the ticies. The principle is this: The state of a system of bodies in which the primitize contitions of motion hane disappeared by the resistance it meets uith, is periodicul, as well as the forces which animate it. I3y reumiting this priciple to that of the coexistence of vory small iscillations, I have obtained an expression for the height of the tilles, of which the arbitrary cuantities comprise the efiect of the local circumstances of the port. To deduce this, I have reciuced the generating e pression of lunar and solar forces acting nom the ocean into a series containing the sines aurl conines of angles in.creasing proportionally to the time. Each term of the serie: may be considered as representing the action of another object, which moves uniformly at a constant dictance, in the plane of the cquator. Thence arise severnl kinds of partinl tiles, the periods of wheh are about half a huar day, a diy, a month, a half-year, a year; and lastly, eighteen years and a hali, which in the duration of the periodical motion of the nodes of the lunat orbit.

Ii) the book which I have quoted of the Mécanirgue Céleste, I have compared this theory with the observatious made at Brest at the commencement of the last centuy; and 1 hare determined the constant arbitrary quantities relative to this port. I was curions to sce whether these circumstances were found to be the same by the observations made a century afterwards, or whether they have experienced any alteration by the changes which the operations of nature and ari have produced, either at the bottom of the sca or in the poit, and on the adjacenis coasts. The result of this impuiry is, that the actual heights of the tides, in the port of Erest, surpass the heights deternined by the old observations by alout $\frac{1}{4}$ th. One part of this difference may arise from the distance of the points where these observations were male; another part may be attributed to the errors of the obscrvations: but thuse two causes do not seem to me suffeient to produce the whole difference which indicate with preat probability a secular change in the action of the sul and momu on the tides of grest, if we could be woll assurer of the exactuess of the graduntions of the oli scale, and taking into accomst its incliration to the hoyzon. But the uncertainty we are in with reipect to this point, does not permit us to pronounce upon this changr, which ought in future to fix the attention of observers. In other respets the agreement is surprising between the old and the nodern observitions, as well as the theory; with regard to the variations of the heights of the tides depending on the declinations and distances of the 
heavenly bodies from the earth, and the laws of their increase and decrease in proportion as they recede from their maximum and from their minimum. In the Mécanique Céleste I had not considered those laws relatively to the variations of the distances of the moon from the earth. Here $I$ take them into consideration, and I find the same agreement between the observation and the theory.

The retardation of the greatest and least tides which follow the times of syoygies and yuadratures, was observed by the ancicnts themselves, as we read in Pliny the naturalist. Daniel Bernouilli, in his paper on the Tides, that gained the prize projosed in 1740 by the Academy of Sciences, attributes this retardation to the inertia of the water; and perhaps also, arids he, to the time taken by the action of the moon to transmit itself to the earth. But I have proved in the fourth book of the Mécanique Céleste, that by allowing for the inertia of the water, the highest tides would concide with the syzygies, if the sea covered uniformly the whole surface of the earth. As to the time of the transmission of the action of the moon, I have discovered by a comparative view of the whole of the celestial phænomena, that the attraction of matter is transmitted with a velocity incomparably greater than eren the velocity of light itself. We must therefore seek some other cause for the retardation in question. I have proved in the book quoted abore, that this cause is the rapidity of the motion of the celestial. body in its orbit, combined with the local circumstances of the port. I have remarked, morcover, that the same cause may increase the ratio of the action of the moon on the sea to that of the sun; and I have given a method of determining this increase by means of the observations, the idea of which is this: Let us suppose the motion of the sun to be uniform:-if we consider only the great inequality of the tides whose period is about half a day, the solar tide is decomposed very nearly into two others, which are cxactly those that would be produced by two celestial bodies moving uniformly, but with different velocities, in the plane of the eyuator, at the mean distauce of the sun from the earth. The mass of the first body is that of the sun, multiplied by the cosine of the inclination of the exliptic to the equator: its motion is that of the sun in its orbit. The second body constantly corresponds with the spring equinox, and its mass is that of the sun multiplied by the half of the square of the sine of the obliquity of the ecliptic. At the equinox these bodies are either in conjunction or in opposition, and the tide is the sum of the tides produced by each of them:-at the solstice the bodies are in quadrature, and the tide is the difference of these partial tides. The observations of the solar tide in these two points show, 
show, therefore, the relation of the partial tiles, and consequently the ratio of the actions of the heavenly bodies on the ocean; and by comparing it to the ratio of their manscs, the increase prodiced on it by the difference of their notion will be determined.

This increase is almost insensible for the sun, on account of the slowness of its motion; but it is very evident for the moon, whose molion is thirteen times more ripid, and whose action on the sea is nearly three times greater.

By comparing in the fouth book of the Mécrmique Céleste. the observations of equinoctial and solstitial tides in the syzygies and the quardratures, I was led by this method to an increase of at least a tenth in the ratio of the action of the moon to that of the sun; but I remarked that an element so delicate ought to be determined by a greater number of observations. The co!lection of modem observations has procured me this advantage. 'These observations, employed in douhle number, confirm the increase indicated by the ancient observations, and ther make it more than one-cighth. Another method foinded on the comparison of the tides towards the apogeum and perigeum of the moon, and applied to the ancient as well as modern observations, leads us also to a similar recult. - Thus the increase of the action of the heavenly bodies on the ticles in the port of Brest ought not to leave any doubt.

The results of observations being always susceptible of errors, it is necessary to know the probability thiat those errors are contained within given limits. It is conceived, and with truth, that the probability remaining the same, those limits are the more dininished as the olsservations are more numerous, and agree better with each other. But this general view of the subject is not sufficient to warrant the exactness of the results of obse1vations and the existence of regular causes which they seem to point out. Sometimes, indeed, it has induced us to seek for the cause of phænomena which were only the accidents of chance. The calculation of probabilities can alone enable us to appreciatc these objects, which renders its une of the highest importance in physical and noral sciences. The preceding researches afforded me an opportunity too faronable to be neglected, of applying the new formule which I have obtained in my 'Theorie analytique des Probalilités, to one of the grandest pliznomena of nature. I there explain at full length the application I have made of it to the laws of the tides. Niy object has been, not only to confirm the truth of those laws, but to trace the way which must be pursued in applications of this kind. Among these laws, the most delicate are those of the increase and decrease of the tides towards their maximum and their minimum, and the influence which the declinations of the heavenly bodjes 
and the variation of their distances from the earth, exercise in this respect. It is evident that these laws are determined by the observations with extreme precision and probability, which explains the romarkable agreement between the results of nodern oberrations with those which the old observations had given the, and with the theory of gravitation. Acerrling to this theory, the action of the noon on the sea follows the inverse ratis of the cube of its dintance from the centie of the earth; and this law regrenents the obrerations of the tides with such exactness, that by these shservations alone the law of attraction boing reciprocally as the square of the dintances might be determined.

My principal desire wa; to apply my formula of probability to the increas of the action of the mocn on the tides, depenting on local circunistances. To decomine this, the preceding observations have funishes me with siateen equations of contition, and from them I have determined this incrcase to he equal to the $\frac{13}{103}$ part of the action of the monn on the ocean. By applying iny fommlin to this restlt, I find that there are 21, tive chances to one, that the local circumstances of the port of Brest increase the ratio of the action of the moon on the tites to that of the sun: this increase may therefore be considered as certain; but there are only fourteen chances to one that the preceding value is not in errcr one half. We must therefore wait for nẹv observations to obtain it with great probabi. lity of being mistaken by only very small quantities.

The ratio of the actions of the moon and of the sun cn the sea, corrected for the effect of hocal circumstances, is very important to be known, becanse it determines the coefficients; Ist, of the terrestrial nutation; $2 \mathrm{dly}$, of the inequality of the precession of the equinoxes; and Sdly, of the lunar equation of the stn's motion. Newton and Daniel Bernouilli had deduced this ratio from the phanenena of the tides, but without having regard to the correction i have just spoken of, which they did not susnect. The ratio which thave detemined, and corrected by the whole of the preceding olservations, gives the miss of the moon equal to $\frac{1}{6}$; that of the earth being unity. It thereiore gives in sexigesinal seconsis, $9 \cdot 65^{\prime \prime}$ for the cocfieient of the mutation; which sirpan-es the cueficient determined be the observations of Makeline only by $\mathrm{T}$ is of a second. Ny formule of probalbility show that there are 21,400 chances to ne, that the nutation is not below $9 \cdot 31^{\prime \prime}$, and there are the same number of chances to one, that it is not above 9.94". Acrorling to this sime ratio the coeficient of the inequality of the precession is 1804 , and that of the lumar ecquation of the solar tables is $7 \cdot 56^{\prime \prime}$, which differs from the coefficient that M. Dclambie found directly from the examination 
of a great number of solar observations only by 7.65 of a second. In this calculation, I have supposed the mean parallax of the sur equal to $8 \cdot 59^{\prime \prime}$, corresponding with that which 1 have deduced from my theory of the moon, comprared with the inequality of the lumar motion, known by the name of parallactic ineguality, and which MI. Burckhardt has determined by means of a very great number of olscrvations. M. Ferère, a learned Spanish astrononer, has lately confined this parallax by a new investigation of the transit of Veuts in 1769 ; in which, by his om olservations, he has corrected the latitude and longitude of plaees where this transit has been observed in America. 'The agreement between all these computations determined by phrenomena so vague, is an additional confirmation of the principle of universal gravitation.

XXVII. A new Instrument for comparing Linear Measures. By M. DE PRONY*.

$\mathrm{T}$

He comparison of linear measires, when great accuracy is necessary, requires careful and delicate operations, as well as the use of inachnery not generally employed in commercial concerns, and dillicult to be procured. I have already published the description of an instrument of this lind, invented and made by M. Lenoir, member of the Board of Longitude, which is as perfect as can be wished; but its expense and size put it out of the power of common obscrvers to procure, and render it uscless to trivellers, who wish to know the proportion betreen some given standard, and the linear measures of an courtry through which they may pass.

I have had made for my onn use, a compurer, which joins the two advatatios of oeconomy and portability: all the pieces of which it is composed nay be fitted into a box of the size of a quarto book. The dearest part is a microscope; but even this requires nothing biterent from those with which observers are commosily furnished. In general it is only necessary to be at the expense of making three audirional pieces, which I shall describe presently.

The properties and use of my comparer are founded on the progress which the art of dividing a right line has made within the last half century. This instrument has therefore, independently of the above advantages, that of requiring no verniter nor micrometer screw, \&c.

It is well known that M. Richer, one of the first artists of Paris for the construction of mathenatical instruments, has

$$
\text { * Cumminicated ly Dr. Fran: }
$$

